\title{
EDUCAÇÃO DE QUALIDADE E O DESENVOLVIMENTO DE COMPETÊNCIAS NA EDUCAÇÃO A DISTÂNCIA: REFLEXÕES A PARTIR DO PROJETO PEDAGÓGICO.
}

\author{
Dirléia Fanfa Sarmento ${ }^{1}$ \\ Jardelino Menegat ${ }^{2}$ \\ Mary Rangel ${ }^{3}$
}

\begin{abstract}
Resumo
As reflexões ora apresentadas são decorrentes de uma pesquisa teórica cuja temática investigativa é o direito à educação de qualidade (articulado ao direito à aprendizagem) e seus modos de efetivação em diferentes contextos. Neste texto fazemos um recorte no Projeto Pedagógico para a Educação a Distância de uma Instituição de Ensino Superior Comunitária, compreendendo que a educação de qualidade pressupõe a existência de um ideário educativo, o qual se explicita por meio deste documento. A análise documental, por meio da Técnica de Análise de Conteúdo, teve por base as seguintes questões: a) Quais são os fundamentos, os princípios e as concepções que orientam o Projeto Pedagógico para a EaD, com vistas a oferta de uma educação de qualidade? b) O desenvolvimento de competências, por meio dos processos de ensino e aprendizagem, é contemplado no Projeto Pedagógico? Em caso afirmativo, quais são as perspectivas didático-pedagógicas sugeridas para efetivar o desenvolvimento das competências? Os resultados apontam o alinhamento institucional em termos documentais, em relação aos fundamentos, princípios e concepções. Apesar de serem explicitadas as perspectivas didático-pedagógicas a serem adotadas na EaD, a reflexão acerca do desenvolvimento de competências ainda é incipiente no Projeto analisado.
\end{abstract}

Palavras-chave: Educação de qualidade; Projeto Pedagógico; Competências; Educação a Distância.

\footnotetext{
${ }^{1}$ Doutora em Educação pela Universidade Federal do Rio Grande do Sul (Porto Alegre/Brasil). Pós-doutorada em Educação pela Universidade do Algarve (Algarve/Portugal). Pós-doutorada em Educação pela Universidade Federal Fluminense (Rio de Janeiro/Brasil). Professora do Programa de Pós-graduação da Universidade La Salle (Canoas/Brasil).

${ }^{2}$ Doutor em Educação pela Universidade La Salle (Canoas/Brasil). Doutor em Administração pela Universidad de la Empresa, do Uruguai. Pós-doutorado em Educação pela Universidade Federal Fluminense, do Rio de Janeiro. Professor do Programa de Pós-graduação da Universidade Católica de Petrópolis (Rio de Janeiro/Brasil). ${ }^{3}$ Doutora em Educação (Universidade Federal do Rio de Janeiro). Pós-doutora em Psicologia Social (Pontifícia Universidade Católica de São Paulo/Brasil). Pesquisadora Nível 1D do CNPq. Professora do Programa de Pósgraduação em Educação da Universidade Federal Fluminense.
} 


\title{
QUALITY EDUCATION AND THE DEVELOPMENT OF COMPETENCES IN DISTANCE EDUCATION: REFLECTIONS FROM THE PEDAGOGICAL PROJECT.
}

\begin{abstract}
The reflections presented here are derived from a theoretical research whose investigative theme is the right to quality education (articulated to the right to learning) and its modes of implementation in different contexts. In this text we make a cut in the Pedagogical Project for Distance Education (EaD) of a Community Higher Education Institution, understanding that quality education presupposes the existence of an educational ideology, which is made explicit through this document. The document analysis through the content analysis technique, had the following questions based on: a) What are the fundamentals, principles and concepts that guide the Educational Project for distance education, in order to offer quality education ? b) The development of skills, through the teaching and learning processes, is contemplated in the Pedagogical Project? If so, what are the didactic-pedagogical perspectives suggested to effect the development of competences? The results point to the institutional alignment in documentary terms, in relation to the fundamentals, principles and conceptions. Although the didactic-pedagogical perspectives to be adopted in the EaD are explained, the reflection about the development of competences is still incipient in the Project analyzed.
\end{abstract}

Keywords: Quality education; Pedagogical project; Skills; Distance Education.

\section{INTRODUÇÃO}

O direito a educação de qualidade, como um direito a ser assegurado a todos, ao lado dos demais direitos fundamentais a dignidade da pessoa, tem sido defendido em vários Marcos Regulatórios da Educação, tanto no âmbito nacional (Constituição Federal/1988, Lei de Diretrizes e Bases da Educação Nacional/1996, Plano Nacional de Educação/2014, dentre outros) quanto no internacional (por exemplo, a Declaração Mundial sobre Educação para Todos/1990; o documento Marco de Ação de Dakar- Educação para Todos: assumindo nossos compromissos coletivos/2000; e o documento Educação 2030 - Declaração e Marco de Ação de Incheon: Rumo a uma educação de qualidade inclusiva e equitativa e à educação ao longo da vida para todos/2015.

A qualidade educacional precisa ser concebida numa perspectiva multidimensional, 
Vol.11 - №19 - JANEIRO - 2019 - ISSN: 1982-6109

pois o conceito de qualidade é polissêmico e complexo e requer um olhar acerca do conjunto de fatores que podem interferir para que ela se efetive ou não. (GARCÍA, 1999; SILVA, 2009; DAVOK, 2007; DOURADO, OLIVEIRA, SANTOS, 2007; DOURADO, OLIVEIRA, 2009). Para Dourado, Oliveira e Santos (2007, p.7):

A análise da Qualidade da Educação deve se dar em uma perspectiva polissêmica, uma vez que essa categoria traz implícitas múltiplas significações. O exame da realidade educacional, sobretudo em vários países da Cúpula das Américas, com seus diferentes atores individuais e institucionais, evidencia que são diversos os elementos para qualificar, avaliar e precisar a natureza, as propriedades e os atributos desejáveis ao processo educativo, tendo em vista a produção, organização, gestão e disseminação de saberes e conhecimentos fundamentais ao exercício da cidadania.

Em consonância com os principais Marcos Regulatórios da Educação que tratam sobre este tema, entendemos a educação de qualidade como aquela que viabiliza o direito à aprendizagem, proporcionando aos estudantes a possibilidade de se desenvolver integralmente, tanto nos espaços educativos formais e ou informais quanto ao longo de toda sua vida. Nessa perspectiva, pelos menos dois aspectos são fundamentais: o desenvolvimento de competências que viabilizem a autonomia cognitiva e a interação com as tecnologias.

Documentos difundidos pela Organização das Nações Unidas para a Educação, a Ciência e a Cultura (UNESCO) que problematizam e estabelecem metas a serem cumpridas pelos países signatários relativas à efetivação do direito à educação de qualidade, têm apontado a questão da exclusão digital e do surgimento dos denominados analfabetos tecnológicos, isto é, aqueles que não conseguem interagir com os artefatos tecnológicos, devido a vários fatores.

Em 1990, a Declaração Mundial sobre Educação para Todos (UNESCO, 1990) já alertava para o fato que "mais de um terço dos adultos do mundo não têm acesso ao conhecimento impresso, às novas habilidades e tecnologias, que poderiam melhorar a qualidade de vida e ajudá-los a perceber e a adaptar-se às mudanças sociais e culturais" (UNESCO, 1990). Em 2000, o Marco de Ação de Dakar-Educação para Todos: assumindo nossos compromissos coletivos, retoma as prioridades estabelecidas na Declaração Mundial sobre Educação para Todos (UNESCO, 1990) e traça como uma de suas metas: "Utilizar as novas tecnologias de informação e comunicação para ajudar a atingir os objetivos da EPT 
Vol.11 - №19 - JANEIRO - 2019 - ISSN: 1982-6109

[Educação para Todos]”. (UNESCO, CONSED, AÇÃO EDUCATIVA, 2001. Em 2009, a

Conferência Mundial sobre a Educação Superior (UNESCO, 2009) faz o seguinte destaque:

\begin{abstract}
A educação superior deve atualizar a educação dos professores [...] com um currículo que prepare os professores para formar indivíduos com o conhecimento e as habilidades que eles precisam para o século 21. Isso demandará novas abordagens, inclusive ensino a distância (EAD) e tecnologias de Informação e Comunicação (T.I.C). [...] A aplicação de T.I.C para ensinar e aprender tem um imenso potencial para aumentar o acesso, a qualidade e o sucesso. A fim de garantir que a inclusão de T.I.C. agregue valor, instituições e governo devem trabalhar juntos para trocar experiências, desenvolver políticas e fortalecer a infraestrutura [...] Expandir o acesso traz desafios à qualidade do ensino superior. Garantia de qualidade é uma função fundamental na educação superior contemporânea e deve envolver investidores. Qualidade requer estabelecer sistemas que garantam a qualidade e padrões de avaliação assim como promover a qualidade cultural dentro das instituições.
\end{abstract}

No ano de 2015, o documento A Educação 2030 - Declaração e Marco de Ação de Incheon: Rumo a uma educação de qualidade inclusiva e equitativa e à educação ao longo da vida para todos enfatiza que a agenda educacional até 2020 será a inclusão e a equidade, "para que todos tenham oportunidades iguais e ninguém seja deixado para trás [...]. Todas as pessoas deveriam ter acesso à educação de qualidade inclusiva e equitativa, bem como a oportunidades de aprendizagem ao longo da vida" (UNESCO, 2015a). Prossegue o documento evidenciando que, diante das diferenças interculturais e globais ocasionadas pelas tecnologias virtuais:

Precisa-se, urgentemente, que crianças, jovens e adultos desenvolvam, ao longo da vida, as necessidades e as competências flexíveis de que necessitam para viver e trabalhar em um mundo mais seguro, sustentável, interdependente, baseado em conhecimentos e guiado pela tecnologia (UNESCO, 2015a).

A Educação a Distância (EaD) tem se constituído numa possibilidade de acesso, de socialização e de difusão dos conhecimentos, sendo prevista em todos os níveis e modalidades, desde a Educação Básica a Educação Superior (BRASIL, 2017, cf. Arts. $8^{\circ}$ e 11). $\mathrm{Na} \mathrm{EaD} \mathrm{a} \mathrm{"mediação} \mathrm{didático-pedagógica} \mathrm{nos} \mathrm{processos} \mathrm{de} \mathrm{ensino} \mathrm{e} \mathrm{aprendizagem}$ ocorre com a utilização de meios e tecnologias de informação e comunicação, com estudantes e professores desenvolvendo atividades educativas em lugares ou tempos diversos" (BRASIL, 2017, Art. $\left.1^{\circ}\right)$.

Em relação a Educação Superior, foco de nossa reflexão, é notório, em todo o país, o 
Vol.11 - №19 - JANEIRO - 2019 - ISSN: 1982-6109

desenvolvimento desta modalidade educacional. Usamos aqui o termo desenvolvimento como sinônimo para crescimento, expansão, em diversas frentes: vemos aumento na oferta de cursos, no número de instituições credenciadas, na variedade dos modelos e metodologias, na disponibilização de serviços e produtos, sobretudo tecnológicos, no número de estudantes que optam por esta modalidade. Uma pesquisa realizada pela Associação Brasileira de Mantenedoras do Ensino Superior (ABMES), em março de 2018, divulgou a informação de que, considerando a continuidade do crescimento atual no número de matrículas, o número de ingressantes na modalidade a distância será maior que o da presencial em 2023.

Mediante o exposto, neste texto refletimos sobre a educação de qualidade e o desenvolvimento de competências na Educação a Distância, tendo como ponto de partida a análise do Projeto Pedagógico para a $\mathrm{EaD}$ de uma Instituição de Ensino Superior Comunitária. Entendemos que a educação de qualidade, independentemente do nível de ensino, pressupõe a existência de um projeto pedagógico que explicite o ideário educativo em termos de fundamentos, princípios, concepções e perspectivas-didático pedagógicas. Neste ideário, interessa-nos identificar se ele contempla o desenvolvimento de competências nos processos de ensino e aprendizagem, considerando-as, conforme já mencionado, fundamentais para o aprender a aprender e a aprendizagem ao longo da vida.

Assim, em termos de estrutura textual, inicialmente introduzimos a temática analítica. A seguir, apresentamos a abordagem metodológica adotada para o desenvolvimento do estudo. Na continuidade, discorremos sobre a análise documental do Projeto Pedagógico da EaD. Por fim, nas considerações finais, retomamos os principais pressupostos abordados.

\section{ABORDAGEM METODOLÓGICA}

As reflexões ora apresentadas são decorrentes de uma pesquisa teórica, de cunho documental e bibliográfico (Gil, 2012), cuja temática investigativa é o direito à educação de qualidade (articulado ao direito à aprendizagem) e seus modos de efetivação em diferentes contextos. Gil (2012, p.51) indica que a diferença entre a pesquisa bibliográfica e a documental reside na "natureza das fontes":

A pesquisa documental assemelha-se muito à pesquisa bibliográfica. A única diferença entre ambas está na natureza das fontes. Enquanto a pesquisa bibliográfica se utiliza fundamentalmente das contribuições dos diversos autores sobre 
Vol.11 - №19 - JANEIRO - 2019 - ISSN: 1982-6109

determinado assunto, a pesquisa documental vale-se de materiais que não receberam ainda um tratamento analítico ou que ainda podem ser reelaborados de acordo com os objetivos da pesquisa.

No texto em tela, nosso olhar se direciona para o contexto da Educação a Distância, tendo como referência a análise documental (Cervo, Bervian, 2002; Marconi, Lakatos, 2006) do Projeto Pedagógico para a Educação a Distância de uma Instituição de Ensino Superior Comunitária, situada na Região Metropolitana de Porto Alegre. Esse documento se constitui numa referência institucional para a oferta de cursos de graduação, pós-graduação e extensão na modalidade a distância.

Nesta análise partimos das seguintes questões norteadoras: a) Quais são os fundamentos, os princípios e as concepções que orientam o Projeto Pedagógico para a EaD, com vistas a oferta de uma educação de qualidade? b) $\mathrm{O}$ desenvolvimento de competências, por meio dos processos de ensino e aprendizagem, é contemplado no Projeto Pedagógico? Em caso afirmativo, quais são as perspectivas didático-pedagógicas sugeridas para efetivar o desenvolvimento das competências?

A Instituição, cujo projeto se constitui em foco analítico, caracteriza-se em termos de categoria administrativa como uma IES Comunitária. De acordo com a Lei $\mathrm{N}^{\circ} 12.881$, de 12 de novembro de 2013, em seu artigo $1^{\circ}$ :

As Instituições Comunitárias de Educação Superior são organizações da sociedade civil brasileira que possuem, cumulativamente, as seguintes características: I - estão constituídas na forma de associação ou fundação, com personalidade jurídica de direito privado, inclusive as instituídas pelo poder público; II - patrimônio pertencente a entidades da sociedade civil e/ou poder público; III - sem fins lucrativos, assim entendidas as que observam, cumulativamente, os seguintes requisitos: a) não distribuem qualquer parcela de seu patrimônio ou de suas rendas, a qualquer título; b) aplicam integralmente no País os seus recursos na manutenção dos seus objetivos institucionais; c) mantêm escrituração de suas receitas e despesas em livros revestidos de formalidades capazes de assegurar sua exatidão; IV - transparência administrativa, nos termos dos arts. $3^{\mathrm{o}}$ e $4^{\mathrm{o}}$; $\mathrm{V}$ destinação do patrimônio, em caso de extinção, a uma instituição pública ou congênere.

A trajetória institucional com a modalidade a distância remonta ao ano de 2001, quando a Instituição passou a integrar a Rede de Instituições Católicas de Ensino Superior (RICESU). Em 2003 foi constituída a Comissão de Educação a Distância, visando a elaboração de um Plano Piloto com os aspectos a serem observados para o credenciamento e a 
Vol.11 - №19 - JANEIRO - 2019 - ISSN: 1982-6109

oferta de cursos de graduação e pós-graduação lato sensu em EaD. Cursos de formação continuada foram ofertados ao corpo docente com o intuito de prepará-lo para atuar nessa modalidade.

Em 2004 teve início a experiência da oferta de disciplinas com 20\% a distância, em consonância com o estabelecido nos dispositivos legais vigentes. No ano de 2008, a Instituição foi credenciada para oferecer cursos de pós-graduação lato sensu, tendo aprovado cinco polos. No ano de 2014, a Mantenedora da Instituição optou em ampliar a atuação na $\mathrm{EaD}$, direcionando-se para cursos de graduação nesta modalidade. Diante disso, várias ações foram realizadas a fim de efetivar o credenciamento institucional para a oferta de cursos de graduação a distância, o que ocorreu no ano de 2016.

Em 2017 e início de 2018 foram realizados os primeiros processos seletivos para o ingresso de estudantes em cursos de graduação na modalidade EaD. (MANTOVANI, SARAIVA, POOL, 2016). Nesta breve contextualização, é possível constatar a jovialidade institucional no que se refere a cursos de graduação integralmente a distância, sendo esta trajetória construída paulatinamente.

Para a análise do Projeto Pedagógico para a EaD adotamos a Técnica de Análise de Conteúdo, que segundo Bardin (2011, p. 124) é definida como: "Um conjunto de técnicas de análise das comunicações, que utiliza procedimentos sistemáticos e objetivos de descrição do conteúdo das mensagens. Tendo presente as questões norteadoras e a leitura flutuante (Bardin, 2011) do Projeto Pedagógico, organizamos os conteúdos em dois eixos temáticos: a) Eixo temático 1: Fundamentos, princípios e concepções, e; b) Eixo temático 2: Perspectivas didático-pedagógicas para o desenvolvimento de competências.

A reflexão acerca desses eixos, apresentada na próxima seção, é realizada de modo articulado por meio de um diálogo com autores identificados na revisão bibliográfica e os dispositivos legais vigentes.

\section{O PROJETO PEDAGógICO PARA A EAD: FUNDAMENTOS, PRINCÍPIOS, CONCEPÇÕES E PERSPECTIVAS DIDÁTICO- PEDAGÓGICAS PARA O DESENVOLVIMENTO DE COMPETÊNCIAS}


Vol.11 - №19 - JANEIRO - 2019 - ISSN: 1982-6109

O Projeto Pedagógico é um dispositivo que explicita o ideário educativo, em termos de fundamentos, princípios, concepções e perspectivas didático-pedagógicas referenciais de uma determinada instituição de ensino. Possui a finalidade de orientar a ação educativa, necessitando ser revitalizado continuamente para que possa atender as demandas educacionais (GADOTTI, 2000; VEIGA, 2009; VASCONCELOS, 2002, 2004). Desse ponto de vista, pode ser considerado "um instrumento teórico-metodológico para a intervenção e a mudança da realidade. É um elemento de organização e integração da atividade prática da instituição neste processo de transformação (VASCONCELOS, 2004, p. 169). De acordo com a Associação Brasileira de Educação a Distância (2012, p.46):

\begin{abstract}
A elaboração de um projeto pedagógico para EAD é, em essência, um processo coletivo, pois da característica multidisciplinar dessa modalidade decorre a necessidade do envolvimento de diferentes especialidades para ser concretizada. $\mathrm{O}$ projeto deve, pois, contemplar diversos olhares sobre um mesmo problema e sua elaboração exige representatividade de várias áreas de conhecimento: pedagógica, de comunicação, de conteúdos e/ou informações, tecnológica e gerencial. A responsabilidade é, portanto, compartilhada, ou seja, é de todos os envolvidos. O projeto pedagógico reflete, nas situações de ensino planejadas, os princípios e valores educacionais que orientaram seu estabelecimento e deve ter como centro de preocupação a aprendizagem dos educandos.
\end{abstract}

O documento Referenciais de qualidade para Educação superior a distância indica que: "Devido à complexidade e à necessidade de uma abordagem sistêmica, referenciais de qualidade para projetos de cursos na modalidade a distância devem compreender categorias que envolvem, fundamentalmente, aspectos pedagógicos, recursos humanos e infraestrutura". (BRASIL, 2007, p.7). Diante disso, no Projeto Pedagógico devem ser contempladas as seguintes dimensões, concebidas de modo articulado:

(i) Concepção de educação e currículo no processo de ensino e aprendizagem; (ii) Sistemas de Comunicação; (iii) Material didático;(iv) Avaliação;(v) Equipe multidisciplinar; (vi) Infraestrutura de apoio; (vii) Gestão AcadêmicoAdministrativa; (viii) Sustentabilidade financeira. (BRASIL, 2007, p.8).

Assim como na modalidade presencial, a EaD possui características e especificidades as quais exigem "administração, desenho, lógica, acompanhamento, avaliação, recursos técnicos, tecnológicos, de infraestrutura e pedagógicos condizentes" (Brasil, 2007), cuja efetivação exige “competências multidisciplinares" (ABED, 2012), tanto por parte dos professores, tutores e demais integrantes da equipe pedagógica quanto dos estudantes. 
Vol.11 - №19 - JANEIRO - 2019 - ISSN: 1982-6109

Mediante tais considerações, passamos a reflexão sobre o Projeto Pedagógico para a Ead, tendo presente a análise documental realizada.

O Projeto Pedagógico para a EaD foi sistematizado por três docentes que atuam na Instituição, considerando-se a trajetória institucional nessa modalidade; as orientações constantes nos dispositivos legais que normatizam a ação educativa na modalidade a distância e os pressupostos de autores que aprofundam a temática em tela.

O documento está estruturado em quatro partes. Inicialmente é realizada a apresentação do documento. A seguir, é explicitada a Organização Institucional para Educação a Distância (Missão Institucional; Planejamento de Programas, Projetos e Cursos a distância; Plano de Gestão para a Modalidade da EAD; Unidade responsável para a gestão de EAD; Planejamento de Avaliação Institucional (Auto avaliação) para EAD; Representação docente, tutores e discente; Estudo para implantação dos polos de apoio presencial; Experiência da IES com a modalidade de educação a distância; Experiência da IES com a utilização de até $20 \%$ da carga horária dos cursos superiores presenciais na modalidade de educação a distância; Sistema para gestão acadêmica da EAD; Sistema de controle de produção e distribuição de material didático (logística), e; Recursos financeiros).

Na sequência, é descrito o Corpo Social (Programa para formação e capacitação permanente dos docentes; Programa para formação e capacitação permanente dos tutores; Produção científica; Titulação e formação do coordenador de EAD da IES; Regime de trabalho do coordenador de EAD da IES; Corpo técnico-administrativo para atuar na gestão em EAD; Corpo técnico-administrativo para atuar na área de infraestrutura tecnológica em EAD; Corpo técnico-administrativo para atuar na área de produção de material didático para EAD; Corpo técnico-administrativo para atuar na gestão das bibliotecas dos polos de apoio presencial; Política para formação e capacitação permanentes do corpo técnico-administrativo).

Por fim, são referidas as Instalações físicas (Instalações administrativas; Infraestrutura de serviços; Recursos de TIC (audiovisuais e multimídia); Plano de expansão e atualização de equipamentos; Biblioteca: instalações para gerenciamento central das bibliotecas dos polos de apoio presencial e manipulação dos respectivos acervos; Biblioteca: informatização do sistema de bibliotecas (que 
Vol.11 - №19 - JANEIRO - 2019 - ISSN: 1982-6109

administra as bibliotecas dos polos de apoio presencial); Biblioteca: política de aquisição,

expansão e atualização do acervo das bibliotecas dos polos de apoio presencial).

a) Eixo temático 1: Fundamentos, princípios e concepções,

Nesse eixo, analisamos o Projeto Pedagógico buscando identificar as articulações em termos de fundamentos, princípios e concepções presentes nesse Projeto com aqueles constantes no Plano de Desenvolvimento Institucional (PDI) e o Plano Pedagógico Institucional (PPI).

O Projeto Pedagógico para a EaD salienta a compatibilidade da missão institucional com a modalidade a distância, considerando que os cursos ofertados pela IES contribuirão para a expansão do acesso, a produção, a apropriação e a socialização do conhecimento. De acordo com o documento:

\begin{abstract}
A missão da IES é compatível e realizável também na modalidade a distância, pois a nova forma de oferta de cursos superiores permitirá que parcelas da população até então não abarcadas pela IES possam participar da comunidade de aprendizagem lassalista. (MANTOVANI; SARAIVA; POOL, 2016, p.6).
\end{abstract}

São descritas as metas estratégicas específicas para a $\mathrm{EaD}$, as quais contemplam a participação institucional e da Rede a qual a IES pertence no segmento da $\mathrm{EaD}$, no contexto nacional; a ampliação do número de estudantes nesta modalidade; a constituição de uma rede de polos e a ampliação gradativa do número de cursos.

Importante destacar que os polos são "unidades operativas, no País ou no exterior, que poderão ser organizados em conjunto com outras instituições, para a execução descentralizada de funções pedagógico-administrativas do curso" (BRASIL, 2005). Ainda, em relação ao polo, o documento Referenciais de qualidade para Educação superior a distância (Brasil, 2007, p.25-25) destaca que ele "desempenha papel de grande importância para o sistema de educação a distância. Sua instalação auxilia o desenvolvimento do curso e funciona como um ponto de referência fundamental para o estudante".

O Projeto retoma os princípios institucionais presentes no PDI, salientando que "Relacionado a esses princípios, está o vínculo da IES com a realidade atual, de expansão da adoção de Tecnologias Digitais (TD) nas práticas educativas, incluindo a oferta de cursos 
Vol.11 - №19 - JANEIRO - 2019 - ISSN: 1982-6109

EaD e o consequente aumento de vagas na educação superior". (MANTOVANI; SARAIVA; POOL, 2016, p.8).

No decorrer do Projeto Pedagógico há um acento na busca de uma cultura para a $E a D$, sendo considerado "necessário o desenvolvimento de competências e habilidades próprias do contexto a distância, tendo em vista que o estudante, nessa modalidade, precisa desenvolver autonomia no processo de aprendizagem, mediado pelo hibridismo e ubiquidade". (MANTOVANI; SARAIVA; POOL, 2016, p.8).

Há, também, uma sinalização que um dos aspectos relacionados a esta cultura é o desenvolvimento e a expansão dos cursos tanto da modalidade semipresencial quanto na modalidade online, o que é compreensível pela trajetória que a Instituição vem percorrendo para consolidar esta modalidade. Inferimos que, ao enfatizar tal cultura, deseja-se chamar a atenção para que, além de criar um portfólio de cursos a distância, é fundamental que todo o corpo funcional, as estruturas acadêmicas e administrativas estejam alinhadas a esta modalidade, compartilhando saberes e experiências colaborativamente.

b) Eixo temático 2: Perspectivas didático-pedagógicas para o desenvolvimento de competências.

Nesse eixo, analisamos o Projeto Pedagógico, fazendo alusão ao currículo e ao processos de ensino e aprendizagem por competências; a mediação e o feedback; e aos subsídios didático-pedagógicos indicados para o desenvolvimento de competências.

Ao falarmos em currículo, temos presente que o mesmo contempla tanto a proposição de um programa formativo oficial que será desenvolvido no decorrer da trajetória do estudante (currículo oficial) quanto os modos de relações e as práticas que se estabelecem para a efetivação desse programa no cotidiano da ação educativa (currículo oculto). Dessa forma, a explicitação de um currículo traduz fundamentos, princípios e concepções acerca do que se idealiza para um determinado itinerário formativo, tendo-se presente o perfil do egresso a ser formado. Se a modalidade da educação a distância possui características 
Vol.11 - №19 - JANEIRO - 2019 - ISSN: 1982-6109

específicas, então a proposta curricular para esta modalidade necessita ser construída considerando-se tais especificidades.

Desse ponto de vista, para maior entendimento, no Projeto Pedagógico analisado poderiam ser contemplados, alguns fundamentos, princípios e concepções relativos a modalidade a distância, especialmente no que se refere a organização do currículo e dos processos de ensino e aprendizagem por competências. Retomamos o exposto no Relatório da Comissão Assessora para Educação Superior a distância, quando ele salienta que:

\begin{abstract}
É preciso considerar os pressupostos filosóficos e pedagógicos que orientam a estrutura do curso e os objetivos, competências e valores que se pretendem alcançar; os aspectos culturais e socioeconômicos tanto no desenho pedagógico do curso, quanto na definição dos meios de acesso aos alunos; uma dinâmica de evolução do processo de aprendizagem que incorpore a interação entre os alunos e professores e dos pares entre si; o desenvolvimento adequado da avaliação do ensino e aprendizagem e do material didático deverá mediar a interação com o aluno, estando este distante do professor e de seus colegas (BRASIL, 2003)
\end{abstract}

Inclusive na modalidade presencial, o desenvolvimento de competências ainda se constitui um desafio na ação educativa, requerendo uma mudança paradigmática especialmente acerca dos processos de planejamento, ensino, aprendizagem e avaliação. Autores tais como Perrenoud (1999), Rios (1999), Le Boterf (2003), Macarenco e Damião (2009), Zabala e Arnau (2010) e Sacristan (2011), dentre outros, tem discutido a questão das competências no âmbito educacional. Sacristan (2011, p. 9) chama a atenção para o fato de que

O conceito de competência é tão confuso, acumula significados de tradições diversas e temos tão pouca experiência para analisar como se poderia realizar na prática, que cabe analisá-lo detidamente e discuti-lo, dando a oportunidade de que, a partir dos avanços produzidos, boas práticas surjam e se desenvolvam.

No entender de Perrenoud (1999, p. 7), a competência pode ser definida como "“[...] uma capacidade de agir eficazmente em um determinado tipo de situação, apoiada em conhecimentos, mas sem se limitar a eles”. Para Rios (1999, p. 79):

Ser competente, ter competência não é somente o cumprimento de fundamentos ou capacidades que foram previamente descritos. Competência não é padrão prescritivo, previamente descrito e estático. É uma construção que se dá ao construir, na caminhada, no coletivo. Nenhuma pessoa se torna competente sozinha. Desta forma, para que se possa ser competente há de se ter uma interdependência entre os pares, nas relações que se estabelecem entre os seres que convivem em um mesmo 
Vol.11 - №19 - JANEIRO - 2019 - ISSN: 1982-6109

ambiente, onde cada um pode demonstrar suas competências, compartilhando e contribuindo para a construção da competência do outro.

Le Boterf (2003, p.40) considera a competência como a “[...] a disposição para agir de modo pertinente em relação a uma situação específica”. Para o autor, “[...] o saber agir não se reduz ao saber operar, deve ir além do prescrito, tomar decisões, iniciativa, fazer escolhas". (LE BOTERF, 2003, p. 38). Para Macarenco e Damião (2009, p. 61):

\begin{abstract}
O modelo de competência é uma ideologia que pode contribuir para o desenvolvimento do potencial humano, na medida em que há um estímulo para o desenvolvimento do potencial do ser humano, envolvendo suas capacidades de pensar, sentir e o agir". "[...] pensar baseado nos conhecimentos, sentir, que lhe permita entrar em contato com sua subjetividade, com o conhecimento de si próprio e do outro, seus limites e seus talentos e os talentos dos outros, sobre aprender a compartilhar, sobre inovar, rever conceitos e abrir espaços mentais para uma nova leitura da realidade". "[...] agir menos reativo, com capacidade de construir alternativas e fazer opções". "[...] remete a liderança pessoal" (grifo das autoras).
\end{abstract}

Pautadas por tal compreensão, as autoras supracitadas categorizam as competências em: a) competências técnicas (conhecimentos e habilidades); b) competências comportamentais (as atitudes), e; c) competências abstratas (a vontade e a entrega). Segundo Zabala e Arnau (2010, p.85), o desenvolvimento de competências pressupõe a articulação entre: “O que é necessário saber? (os conhecimentos, os conteúdos conceituais). O que se deve saber fazer? (as habilidades, os conteúdos procedimentais). De que forma se deve ser? (as atitudes, os conteúdos atitudinais)".

Alinhados com o pensamento de Murad (2008), ao falarmos em competência, temos presente que ela é decorrente da mobilização de um conjunto de conhecimentos, habilidades e atitudes, incluindo-se os valores e a espiritualidade.

Documentos que versam sobre o desenvolvimento de competências na EaD (cf. por exemplo, ABED, 2012), salientam a importância de "um referencial para identificação de competências necessárias ao desenvolvimento de ações EAD de qualidade “ (idem, p.9). Tal referencial seria " um ponto de partida, um conjunto de parâmetros para subsidiar os profissionais de EAD sobre as competências necessárias à realização de ações de EAD com um mínimo de qualidade”. (Ibidem).

Nesse sentido, acrescentar uma matriz de competências necessárias a mediação pedagógica e aquelas competências gerais e específicas que os estudantes precisam 
Vol.11 - №19 - JANEIRO - 2019 - ISSN: 1982-6109

desenvolver, independentemente do curso ou componente curricular, poderia contribuir para um melhor entendimento sobre a ação educativa na modalidade $\mathrm{EaD}$ e a aprendizagem significativa. De acordo com a Associação Brasileira de Educação a Distância (2012, p. 13):

As competências em EAD, gerais e específicas, referem-se ao saber conhecer, saber fazer, saber ser e saber conviver e visam oferecer um quadro referencial, chamado de matriz de competências para o desenvolvimento de ações, assim como dos conteúdos que favorecem a sua aquisição ou desenvolvimento.

No Projeto Pedagógico para a EaD a alusão ao desenvolvimento de competências é feita relacionada a construção da "cultura da EaD", conforme referido, articulando as competências a autonomia do estudante. Entretanto, assim como observado nos fundamentos, pressupostos e concepções, não existe um maior aprofundamento sobre esta questão.

Entretanto, fica o questionamento acerca da compreensão geral sobre as competências, enquanto mobilizadoras de conhecimentos, habilidades, atitudes, valores e a espiritualidade. Apesar do Projeto Pedagógico mencionar de forma ampla as competências, sua abordagem fica relacionada diretamente aos conteúdos. Dito de outra forma, não conseguimos identificar no referido Projeto um acento no desenvolvimento das habilidades e dos aspectos atitudinais, por exemplo, fundamentais de serem considerados numa abordagem pedagógica por competências. Inclusive na avaliação cuja descrição é detalhada, observamos uma lacuna no que se refere a uma abordagem avaliativa por competências.

Além disso, com base na compreensão de que as competências contemplam além da mobilização de conhecimentos, habilidades e atitudes (CHA), também há de ser considerado o desenvolvimento de valores e da espiritualidade (CHAVE), principalmente nas Instituições de cunho confessional, como no caso em tela, cuja filosofia tem como cerne os valores humanísticos e espirituais.

No processo interativo, o Projeto Pedagógico enfatiza a importância da mediação e o constante feedback para os estudantes como uma das formas de acompanhar a aprendizagem, suscitar o diálogo e a participação. Conforme Souza, Sartorib e Roeslerc (2008, p. 331):

$\mathrm{Na} \mathrm{EaD}$, a mediação adquiriu papel de suma importância uma vez que o distanciamento físico sempre esteve a exigir recursos, estratégias, habilidades, competências e atitudes diferentes dos convencionais - pautados na exposição oral e no contato face a face. Com a inserção das tecnologias digitais de comunicação na $\mathrm{EaD}$ e o desenvolvimento de ambientes virtuais de aprendizagem, a função mediadora do professor tomou um forte impulso, pelas possibilidades e também 
Ainda, segundo as autoras supracitadas:

\begin{abstract}
A EaD caracteriza-se por ser um processo composto por duas mediações: a mediação humana e a mediação tecnológica, imbricadas uma na outra. A primeira pelo sistema de tutoria, a segunda pelo sistema de comunicação que está a serviço da primeira para viabilizar a mediação pedagógica. A mediação pedagógica, resultante da concepção planejada entre estas duas mediações, é potencializada pela convergência digital que disponibiliza acesso e portabilidade por meio de dispositivos de comunicação síncrona e assíncrona cada vez mais integrados, velozes e potentes. (Idem, p. 335).
\end{abstract}

São salientadas a proposição de resolução de problemas, desafios e desenvolvimento prático dos conteúdos por meio de uma aprendizagem ativa. Também é referida a interação constante entre pares, professores e os tutores, visando a autoria e coautoria nos processos de ensino e aprendizagem. A viabilização desta interação ocorre, principalmente, por meio dos fóruns temáticos, das webconferências e de chats. Behar et ali (2013, p. 47-48), ao abordar a interação na educação a distância, esclarece que:

[...] entende-se iteração em espaços tecnológicos como a possibilidade de os indivíduos realizarem trocas entre seus pares, entre alunos, entre professores e tutores bem como entre a equipe pedagógica de maneira criativa em uma situação tal que a comunicação possa ter lugar sem que o sujeito se sinta preso à relação açãoreação. Supõe-se que a interação seja baseada em um diálogo que modifica o sujeito, o outro, suas mensagens e suas inter-relações. Na EAD, a interação é entendida como uma "ação entre" os participantes de uma tecnologia digital, geralmente uma ferramenta, recurso e /ou AVA, em que o diálogo entre eles é realizado por meio de sistemas de comunicação (fórum, chat, email, etc), o que pode envolver colaboração e cooperação, sendo esta especialmente importante para a construção de conhecimento na troca possibilitada pelo ambiente virtual. (grifo das autoras).

Nesse sentido, retomamos o documento Referenciais de qualidade para Educação Superior a distância quando ele destaca que a comunicação e o diálogo contribuem para “diminuir a sensação de isolamento, apontada como uma das causas de perda de qualidade no processo educacional, e uma das principais responsáveis pela evasão nos cursos a distância" (BRASIL, 2007, p.13).

As perspectivas didático-pedagógicas a serem adotadas para o desenvolvimento dos conteúdos são bem explicitadas, destacando-se a utilização de e-book interativo (livro didático), objetos de aprendizagem, vídeos, infográficos, games, dentre outros. 
Vol.11 - №19 - JANEIRO - 2019 - ISSN: 1982-6109

Fica evidenciado, também, no Projeto Pedagógico, a produção de subsídios didáticopedagógicos específicos a serem desenvolvidos pelo professor e a utilização de materiais de domínio público, tais como vídeos, podcasts, animações ou simulações. Chama a atenção a descrição sobre o apoio prestado ao professor, havendo um setor específico que oferece assessoria para o design pedagógico e a produção do material didático (design gráfico, diagramação de objetos interativos, gravação e edição de objetos multimídia).

É possível constatar no Projeto Pedagógico uma ênfase no material a ser utilizado para o desenvolvimento dos conteúdos dos cursos, para que os mesmos atendam os padrões de qualidade. Tal ênfase está em consonância com os dados do Censo EAD.BR 2016, o qual destaca que uma das preocupações dos gestores de $\mathrm{EaD}$ é a inovação em abordagens pedagógicas, ainda que os dados deste Censo apontam a variedade de formas como os conteúdos são trabalhados, como por exemplo, por meio de teleaulas, textos digitais que não sejam livros, vídeos, livros impressos e eletrônicos, objetos de aprendizagem, áudios, jogos eletrônicos, simulações online e recursos adaptativos. (ABED, CENSO EAD.BR 2016).

Por fim, apesar de não se constituir em foco de nossa discussão neste texto, merecem destaque no Projeto Pedagógico: a) o detalhamento apresentado no Projeto Pedagógico sobre o Programa para formação e capacitação permanente dos docentes e dos tutores, demonstrando o compromisso institucional com a qualificação constante de seu corpo funcional; b) a descrição sobre os processos avaliativos da Avaliação Institucional, realizada pela Comissão Própria de Avaliação (CPA); c) a contextualização da experiência institucional e de sua trajetória de implantação da modalidade a distância bem como do estudo feito para implantação dos polos de apoio presencial; c) a organização do sistema de gestão acadêmica da EAD; e d) o processo logístico de controle de produção e distribuição de material didático.

Posto isto, passamos as considerações finais.

\section{CONSIDERAÇÕES FINAIS}

As reflexões apresentadas no decorrer do texto tiveram como referência os seguintes questionamentos: Quais são os fundamentos, os princípios e as concepções que orientam o Projeto Pedagógico para a $\mathrm{EaD}$, com vistas a oferta de uma educação de qualidade? b) $\mathrm{O}$ desenvolvimento de competências, por meio dos processos de ensino e aprendizagem, é 
Vol.11 - №19 - JANEIRO - 2019 - ISSN: 1982-6109

contemplado no Projeto Pedagógico? Em caso afirmativo, quais são as perspectivas didáticopedagógicas sugeridas para efetivar o desenvolvimento das competências?

Em termos de síntese, o Projeto Pedagógico para a EaD evidencia seu alinhamento com o Plano de Desenvolvimento Institucional (PDI) e o Projeto Pedagógico Institucional (PPI) em relação aos fundamentos, princípios e concepções. Igualmente, tendo presente os dispositivos legais vigentes, é possível observar que o Projeto contempla os aspectos requeridos para a sua elaboração.

Apesar do documento possuir uma densidade teórica, entendemos que os fundamentos, os princípios e as concepções que conferem uma identidade a modalidade a distância poderiam ter sido explicitados e aprofundados. Da mesma forma, no que se refere as competências, a abordagem conceitual e seus modos de efetivação poderiam ser mais desenvolvidos, contemplando-se além das perspectivas didático-pedagógicas a serem adotadas para o desenvolvimento dos conteúdos, as estratégias para o desenvolvimento das habilidades, das atitudes, dos valores e da espiritualidade.

Retomamos o entendimento de que o "Projeto Pedagógico pode auxiliar, e muito, o desenvolvimento de uma ação educativa em EaD. Torna-se uma bússola para outras decisões necessárias ao processo". (ABED, 2012, p. 52). Dessa forma, "Não deve, no entanto, engessar, mas permitir incorporar ideias, soluções e inovações que apareçam durante o percurso" (Ibidem).

Nessa perspectiva, enquanto um dispositivo dinâmico, o Projeto Pedagógico pressupõe uma revitalização colaborativa contínua de forma a cada vez mais estar em consonância com as demandas educacionais emergentes. Entendemos, também, que cada Instituição, com base nos dispositivos legais vigentes e nas experiências decorrentes de sua trajetória, deve optar pela estrutura que lhes pareça mais adequada para a elaboração deste documento.

Por fim, almejamos que as reflexões ora apresentadas, articuladas a outros referenciais e estudos, possam contribuir para o repensar sobre a relevância do Projeto Pedagógico como norteador das ações educativas, em qualquer modalidade de ensino. 
Vol.11 - №19 - JANEIRO - 2019 - ISSN: 1982-6109

REFERÊNCIAS

ASSOCIAÇÃO BRASILEIRA DE EDUCAÇÃO A DISTÂNCIA (ABED). Competências para a Educação a Distância: matrizes e referenciais teóricos. $<$ Disponível em:http://www.abed.org.br/documentos/Competencias_Final_Ago2012.pdf. Acesso em: 15 fevereiro 2018.>

ASSOCIAÇÃO BRASILEIRA DE EDUCAÇÃO A DISTÂNCIA (ABED). CENSO EAD.BR2016. <Disponível em http://www.abed.org.br/site/pt/midiateca/censo ead/. Acesso em: 15 fevereiro 2018.>

BARDIN, Laurence. Análise de conteúdo. São Paulo: Edições 70, 2011.

BEHAR, Patricia A. et ali. Educação a distância e competências: uma articulação necessária. In: . BEHAR, Patricia A. (org.). Competências em educação a distância. [recurso eletrônico]. Porto Alegre: Penso, 2013, p.42-54.

BRASIL. Constituição da República Federativa do Brasil. Brasília, DF: Senado Federal, 1988.

BRASIL. Lei $\mathbf{n}^{\circ}$ 9.394, de 20 de dezembro de 1996. Estabelece as diretrizes e bases da educação nacional. Diário Oficial [da] República Federativa do Brasil, Brasília, DF, 23 dez.

BRASIL. Ministério da Educação. Relatório da Comissão Assessora para educação Superior a distância. Secretaria de Educação Superior. Brasília, 2003.

BRASIL. Presidência da República. Casa Civil. Subchefia para assuntos jurídicos. Decreto $\mathbf{N}^{\circ}$ 5.622, de 19 de dezembro de 2005. Regulamenta o art. 80 da Lei n o 9.394, de 20 de dezembro de 1996, que estabelece as diretrizes e bases da educação nacional.

BRASIL. Presidência da República. Casa Civil. Subchefia para assuntos jurídicos. Lei $\mathbf{n}^{\mathbf{o}}$ 12.881, de 12 de novembro de 2013. Dispõe sobre a definição, qualificação, prerrogativas e finalidades das Instituições Comunitárias de Educação Superior - ICES, disciplina o Termo de Parceria e dá outras providências.

BRASIL. Presidência da República. Casa Civil. Subchefia para assuntos jurídicos. Lei no 13.005, de 25 de junho de 2014. Aprova o Plano Nacional de Educação-PNE e dá outras providências.

BRASIL. Presidência da República Casa Civil Subchefia para Assuntos Jurídicos. Decreto no 9057, de 25 de maio de 2017. Regulamenta o art. 80 da Lei no 9.394, de 20 de dezembro de 1996, que estabelece as diretrizes e bases da educação nacional.

BRASIL. Ministério da Educação. Secretaria de Educação a Distância. Referenciais de 
Vol.11 - №19 - JANEIRO - 2019 - ISSN: 1982-6109

Qualidade para Educação Superior a Distância: versão preliminar. Brasília, 2007. <Disponível em:

http://portal.mec.gov.br/seed/arquivos/pdf/legislacao/refead1.pdf. Acesso em: 15 maio 2018.>

CERVO, Amado L.; BERVIAN, Pedro A. Metodologia Científica. $5^{\text {a }}$ ed. São Paulo: Prentice Hall, 2002.

DAVOK, Delsi F. Qualidade em Educação. Avaliação, Campinas; Sorocaba, SP, v. 12, n. 3, p. 505-513, set. 2007.

DOURADO, Luis F.; OLIVEIRA, José F., SANTOS, Catarina de A. A qualidade da Educação: conceitos e definições. Série Documental: Textos para Discussão. Brasília, DF, v. 24, n. 22, p. 5-34, 2007

DOURADO, Luis F.; OLIVEIRA, José F. A qualidade da Educação: Perspectivas e desafios. Caderno Cedes, Campinas v. 29, n. 78, p. 201-215, maio/ago. 2009.

GARCÍA, Elena C. Evaluación de la calidad educativa. 2. ed. Organización de Estados Iberoamericanos. Madri: La Muralla, S.A., 1999.

GIL, Antonio Carlos. Métodos e Técnicas de Pesquisa Social. 6 ed. São Paulo: Atlas, 2012.

LE BOTERF, Guy. Desenvolvendo a competência dos profissionais. Porto Alegre. Artmed, 2003

MACARENCO, Isabel; DAMIÃO, Maria de Lurdes Z. Competência, a essência da liderança pessoal: seja o melhor com o melhor do seu talento. São Paulo : Saraiva, 2009.

MANTOVANI, Ana Margô; SARAIVA, Jonas Rodrigues; POOL, Mario Augusto. Projeto Pedagógico para a EaD. CENTRO UNIVERSITÁRIO LA SALLE (UNILASALLE). Canoas, Rio Grande do Sul, 2016.

MARCONI, Marina de A.; LAKATOS, Eva M. Técnicas de pesquisa: planejamento e execução de pesquisas, amostragens e técnicas de pesquisa, elaboração, análise e interpretação dos dados. 6. ed. São Paulo: Atlas, 2006.

MURAD, Afonso T. Gestão e Espiritualidade. São Paulo: Paulinas, 2008.

ORGANIZAÇÃO DAS NAÇÕES UNIDAS PARA A EDUCAÇÃO, A CIÊNCIA E A CULTURA - UNESCO. Declaração Mundial sobre Educação para Todos: satisfação das necessidades básicas de aprendizagem. Jomtien, 1990.

ORGANIZAÇÃO DAS NAÇÕES UNIDAS PARA A EDUCAÇÃO, A CIÊNCIA E A CULTURA - UNESCO. Declaração de Incheon - Educação 2030: Rumo a uma educação de 
Vol.11 - №19 - JANEIRO - 2019 - ISSN: 1982-6109

qualidade inclusiva e à educação ao longo da vida para todos. UNESCO, 2015a.

ORGANIZAÇÃO DAS NAÇÕES UNIDAS PARA A EDUCAÇÃO, A CIÊNCIA E A CULTURA - UNESCO. Marco de Ação - Educação 2030: Rumo a uma educação de qualidade inclusiva e à educação ao longo da vida para todos. UNESCO, 2015 b.

ORGANIZAÇÃO DAS NAÇÕES UNIDAS PARA A EDUCAÇÃO, A CIÊNCIA E A CULTURA (UNESCO). CONSED, AÇÃO EDUCATIVA. Educação para Todos: o Compromisso de Dakar. Brasília: Unesco, Consed, Ação Educativa, 2001.

ORGANIZAÇÃO DAS NAÇÕES UNIDAS-ONU. Declaração Universal dos Direitos Humanos, 1948.

ORGANIZAÇÃO DOS ESTADOS IBERO-AMERICANOS PARA A EDUCAÇÃO, A CIÊNCIA E A CULTURA (OEI). A Educação que queremos para a geração dos bicentenários: Metas Educativas 2021. Madri: OEI, 2008

PERRENOUD, Philippe. Construir Competências desde a Escola. Porto Alegre: Artmed Editora; 1999.

RIOS, Terezinha Azerêdo. Ética e Competências. 7 ed. São Paulo: Cortez, 1999.

SACRISTAN, José Gimeno (Org). Dez teses sobre a aparente utilidade das competências em educação. In: Educar por Competências: o que há de novo? Porto Alegre: ARTMED, 2011.

SILVA, Maria Abádia da. Qualidade social da educação pública: Algumas aproximações. Caderno Cedes, Campinas, vol. 29, n. 78, p. 216-226, maio/ago. 2009.

SOUZA, Alba Regina Battisti de; SARTORIB, Ademilde Silveira; ROESLERC, Jucimara. Mediação pedagógica na educação a distância: entre enunciados teóricos e práticas construídas. Rev. Diálogo Educ., Curitiba, v. 8, n. 24, p. 327-339, maio/ago. 2008.

ZABALA, Antoni; ARNAU, Laia. Como aprender e ensinar competências. Porto Alegre: Artmed, 2010. 


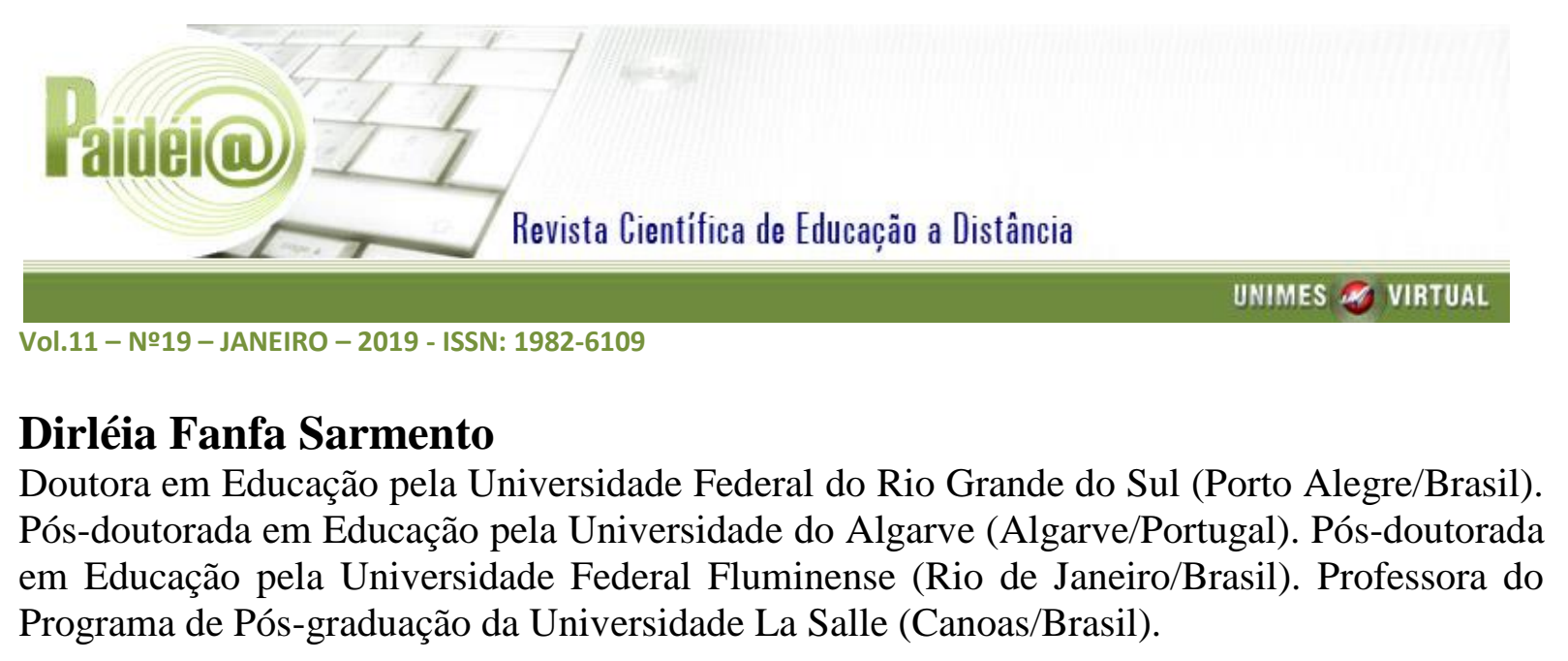

\section{Jardelino Menegat}

Doutor em Educação pela Universidade La Salle (Canoas/Brasil). Doutor em Administração pela Universidad de la Empresa, do Uruguai. Pós-doutorado em Educação pela Universidade Federal Fluminense, do Rio de Janeiro. Professor do Programa de Pós-graduação da Universidade Católica de Petrópolis (Rio de Janeiro/Brasil).

\section{Mary Rangel.}

Doutora em Educação (Universidade Federal do Rio de Janeiro). Pós-doutora em Psicologia Social (Pontifícia Universidade Católica de São Paulo/Brasil). Pesquisadora Nível 1D do CNPq. Professora do Programa de Pós-graduação em Educação da Universidade Federal Fluminense.

\section{Artigo recebido em 30/05/2018}

Aceito para publicação em 29/01/2019

\section{Para citar este trabalho:}

SARMENTO, Dirléia Fanfa; MENEGAT, Jardelino; RANGEL, Mary. EDUCAÇÃO DE QUALIDADE E O DESENVOLVIMENTO DE COMPETÊNCIAS NA EDUCAÇÃOO A DISTÂNCIA: REFLEXÕES A PARTIR DO PROJETO PEDAGógICO. Revista Paidéi@. Unimes Virtual. Volume 11 - Número 19 - Janeiro - 2019 - Disponível em:

\section{http://periodicos.unimesvirtual.com.br/index.php?journal=paideia\&page=index}

